\title{
PENGARUH KEPRIBADIAN TERHADAP PERILAKU PENGGUNAAN ONLINE TRADING DAN PREFERENSI RESIKO PADA INVESTOR
}

\author{
THE EFFECT OF PERSONALITY ON ONLINE TRADING USE BEHAVIOR AND \\ THE RISK PREFERENCE OF INVESTORS
}

\author{
Hasnah Sabrina Siregar*), Wita Juwita Ermawati*), dan Anna Fariyanti**) \\ ${ }^{*}$ Departemen Manajemen, Fakultas Ekonomi dan Manajemen, IPB University \\ Jl. Agatis Kampus IPB Darmaga, Bogor 16680 \\ ${ }^{* *}$ Departemen Agribisnis, Fakultas Ekonomi dan Manajemen, IPB University \\ Jl. Agatis Kampus IPB Darmaga, Bogor 16680
}

\begin{abstract}
One way to obtain information is through online trading, which also serves as a place for transacting. Personality is a factor that affects how a person behaves and makes decisions, including behavioral finance. This research aimed to analyze the effect of investors' personality on online trading use behavior and investors' risk preference. The data were obtained from online questionnaires distributed through social media with a total of 240 respondents. This research used a structural equation modeling (SEM) to measure the relationship between latent variables, namely the five personality variables of the International Personality Pool Item-Big Five Model (IPIP-BFM), investors' risk preference, and online trading behavior. The data were processed using SPSS and SEM-PLS. The result indicated that openness to experience positively and significantly affected online trading use behavior and investors' risk preference. Conscientiousness, extraversion, agreeableness, and neuroticism insignificantly affected online trading use behavior and investors' risk preference. The behavior of using online trading had a positive and significant effect on risk preference. The result showed that if investors were more open to something, they would use online trading more intensely and become more risk-seeker.
\end{abstract}

Keywords: behavioral finance, online trading, personality, risk preference, SEM-PLS

\begin{abstract}
Abstrak: Salah satu media informasi adalah online trading yang berfungsi untuk memperoleh informasi dan tempat bertransaksi bagi investor. Kepribadian merupakan salah satu faktor yang mempengaruhi bagaimana seseorang berperilaku dan membuat keputusan, termasuk perilaku keuangannya. Penelitian ini bertujuan menganalisis pengaruh kepribadian investor terhadap perilaku penggunaan online trading dan preferensi risiko investor. Data penelitian ini diperoleh dari penyebaran kuesioner secara online melalui sosial media berjumlah 240 responden. Penelitian ini menggunakan structural equation model (SEM) untuk mengukur hubungan antara variabel laten yaitu lima variabel kepribadian dari International Personality Item Pool-Big Five Model (IPIP-BFM), terhadap preferensi risiko investor dan perilaku penggunaan online trading. Pengolahan data pada penelitian ini menggunakan software SPSS dan software SEM-PLS. Hasil penelitian ini menunjukkan bahwa openness to experience memiliki pengaruh positif dan signifikan terhadap perilaku penggunaan online trading dan preferensi risiko investor. Conscentiousness, extraversion, agreeableness, dan neuroticism memiliki pengaruh yang tidak signifikan terhadap perilaku penggunaan online trading dan preferensi risiko investor. Perilaku penggunaan online trading memiliki pengaruh yang positif dan signifikan terhadap preferensi risiko. Hasil tersebut menunjukkan, semakin investor memiliki sifat terbuka terhadap sesuatu maka semakin intens penggunaan online trading dan semakin bersikap risk seeker.
\end{abstract}

Kata kunci: kepribadian, online trading, perilaku keuangan, preferensi risiko, SEMPLS

\footnotetext{
${ }^{1}$ Alamat Korespondensi:

Email: hasnahsabrina@gmail.com
} 


\section{PENDAHULUAN}

Investasi merupakan kegiatan keuangan yang sangat penting untuk disadari masyarakat Indonesia, terutama investasiberupa sahamatauinstrumen keuangan lainnya. Kegiatan investasi dapat memberi keuntungan kepada investor dan juga menyejahterakan perekonomian Indonesia melalui peningkatan penerimaan pajak negara dan percepatan aktivitas perekonomian nasional dengan mempermudah perusahaan memperoleh dana demi menunjang kegiatan ekspansinya yang berdampak pada perluasan kegiatan bisnis sehingga perusahaan membuka lapangan pekerjaan baru.

Kahneman dan Tversky (1979) mengungkapkan bahwa pengambilan keputusan oleh investor tidak selalu dilakukan dengan rasional, sering kali investor dipengaruhi oleh pemikiran yang tidak rasional. Faktor psikologis ini menyebabkan timbulnya bias dalam persepsi investasi yang akan diambilnya. Bias persepsi merupakan kecenderungan psikologis yang menyebabkan seseorang yang kehilangan objektivitas akan suatu persepsi dan situasi (Chopde dan Kulkarni, 2017). Bias psikologis ini dapat dipengaruhi oleh kepribadian setiap investor yang berbeda-beda. Ada beberapa alat ukur kepribadian yang sering digunakan dalam test psikologi yaitu Myers Briggs Type Indicator (MBTI) oleh Jung tahun 1921, teori Dominant, Influence, Steadiness, dan Compliant (DISC) oleh Martson tahun 1920, dan Big Five Factor (BFF) oleh Goldberg tahun 1981 (Wandrial, 2014; Angganantyo, 2014; Indriani, 2014). Namun, alat ukur kepribadian oleh Goldberg (1992) dinilai lebih baik dan lengkap dengann kemudian menyusun IPIP-BFM-50, yaitu versi singkat dari 3.329 item yang terkumpul dalam International Personality Item Pool (IPIP) website menjadi 50 item yang kredibel, kemudian pada penelitian ini disesuaikan kembali menjadi 48 item.

Preferensi risiko merupakan bentuk apakah investor bersikap risk averse, risk neutral, ataupun risk seeker. Risk averse merupakan kondisi dimana investor akan melepas aset yang ia miliki untuk menghindari risiko. Risk neutral adalah kondisi dimana investor akan mengabaikan risiko yang terjadi. Risk seeker adalah kondisi dimana investor akan mempertahankan aset yang ia miliki dan bersedia menanggung risiko yang akan terjadi (Halim, 2005). Preferensi investor dalam membuat keputusan investasi dapat disebabkan oleh kondisi psikologisnya.
Perkembangan dunia investasi sangat dipengaruhi oleh teknologi dimasa industri 4.0 ini, yaitu industri digital. Pada tahun 2002 BEJ kemudian meluncurkan sistem perdagangan jarak jauh (remote trading) yang memungkinkan investor untuk melakukan transaksi tanpa harus ke lantai bursa karena transaksi dapat langsung dikirim ke sistem JATS. Ini merupakan cikal bakal dari adanya online trading sehingga semakin menambah kemudahan bagi investor dalam melakukan transaksi saham. Pada tahun 2011 seluruh transaksi dilakukan secara online.

Semakin mudahnya investor dalam melakukan transaksi investasi menggunakan online trading, seringkali membuat investor melupakan risiko-risiko yang ada. Didier dan Schmukler (2014) mengungkapkan inovasi dibidang keuangan dengan adanya produk dan layanan yang ditawarkan oleh lembaga keuangan membuat individu sulit untuk berinvestasi secara bijak. Abreu dan Mendes (2012) menyatakan semakin sering investor memperoleh informasi maka akan semakin sering juga investor melakukan transaksi. Menurut Tauni et al. (2017) kemudahan memperoleh informasi dapat meningkatkan frekuensi transaksi oleh investor. Peningkatan frekuensi transaksi dari biasanya dapat menyebabkan volatilitas saham menjadi meningkat (Wulfmeyer, 2016). Vidayana (2012) menyebutkan bahwa investor di Indonesia yang menggunakan sistem perdagangan saham online memiliki tingkat kekhawatiran yang rendah terhadap resiko. Ada banyak risiko yang dapat terjadi ketika berinvestasi di pasar modal, baik itu risiko makro ekonomi maupun mikro ekonomi. Sejak tahun 2011 yaitu tahun dimana seluruh aktifitas investasi digunakan menggunakan online trading, terjadi beberapa fenomena ekonomi makro di Indonesia yang beriringan dengan peningkatan ratarata nilai dan frekuensi perdagangan oleh investor. Ringkasan pergerakan data rata-rata nilai transaksi harian $(\mathrm{RNTH})$, rata-rata frekuensi transaksi harian, indeks harga saham gabungan (IHSG), suku bunga, dan inflasi tahun 2011-2019 disajikan dalam Gambar 1

Gambar 1 memperlihatkan bahwa pergerakan kurva antara rata-rata nilai dan frekuensi transaksi tampak berbanding lurus, walaupun rata-rata nilai transaksi terlihat lebih fluktuatifdibandingkan frekuensi transaksi. Pada tahun 2013 terjadi penurunan indeks harga saham gabungan (IHSG) yang merupakan bentuk dari risiko pasar yang dihadapi investor. Namun, dilihat kurva RNTH pada tahun 2013 tampak berbanding terbalik dengan IHSG. Ini dapat disimpulkan bahwa pada 
tahun tersebut investor Indonesia cukup berani untuk melakukan transaksi dan menghadapi risiko pasar. Kemudian pada tahun 2012 hingga 2014 Indonesia mengalami inflasi yang cukup tinggi. Inflasi menjadi risiko bagi investor karena inflasi dapat mengurangi nilai investasi yang dimiliki investor. Walaupun terjadi inflasi yang tinggi, tampak nilai transaksi yang diperdagangkan investor terus terjadi peningkatan terutama pada tahun 2013, sedangkan pada tahun tersebut tingkat inflasi merupakan yang paling tinggi. Tampak sepertinya investor tidak begitu khawatir dengan risiko yang sedang dihadapi. Suku bunga dapat membuat biaya investasi oleh investor lebih mahal, sehingga menurunkan nilai investasinya. Suku bunga juga merupakan risiko yang harus dihadapi investor, dimana tampak dari tren pada Gambar 2, suku bunga, RNTH, dan frekuensi pada tahun 2018-2019 terjadi peningkatan suku bunga, tetapi nilai dan frekuensi transaksi oleh investor tetap mengalami peningkatan. Tahun 2018-2019 merupakan tahun dimana jumlah investor bertambah sangat signifikan. Hal yang dikhawatirkan adalah banyaknya investor baru yang belum berpengalaman melakukan transaksi tanpa memperhatikan faktor-faktor yang dapat menyebabkan risiko.

Wulandari dan Iramani (2014) menyatakan bahwa preferensi risiko dapat dijadikan sebagai prediktor yang sangat kuat dalam pengambilan keputusan investasi. Rinandiyana et al. (2020) menunjukkan bahwa perilaku perdagangan saham investor klien PT. Reliance Sekuritas Indonesia tidak lepas dari pengaruh preferensi risiko yang dimilikinya. Lolibl dan Hira (2011) menemukan bahwa karakteristik psikologis kepercayaan diri dan toleransi risiko investor menyebabkan perbedaan cara pencarian informasi untuk keputusan investasi. Conlin et al. (2015) menemukan bahwa kepribadian yang merupakan prediktor karakter, signifikan mempengaruhi perilaku perdagangan saham investor di Finlandia. Durand et al. (2013) menemukan bahwa kepribadian yang dimiliki investor memiliki keterkaitan dengan pembentukan harga di pasar. Kepribadian extraversion ditemukan memiliki pengaruh yang negatif dan signifikan terhadap bid ask spread, sedangkan kepribadian agreeableness memiliki pengaruh yang positif dan signifikan terhadap bid ask spread. Eksposur pasar modal secara positif disebabkan oleh adanya sikap extraversion investor dan secara negatif dikarenakan adanya sikap agreeableness investor. Ini disimpulkan ketika investor memiliki sifat yang extraversion membuat mereka akan semakin percaya diri dalam bertransaksi, namun ketika sifat agreeableness lebih dominan membuat kepercayaan diri investor akan menurun dalam melakukan transaksi. Perilaku investor dalam bertransaksi ini yang akan berdampak dalam pembentukan harga di pasar modal. Ini menunjukkan masalah perilaku investor ini tidak hanya berdampak pada investor itu sendiri, namun juga pada kondisi pasar. Perilaku tidak rasional oleh investor dapat menimbulkan risiko volatilitas pasar. Pendekatan yang dapat dilakukan agar risiko ini tidak terjadi adalah dengan memberikan edukasi lebih kepada investor tentang bagaimana berperilaku ketika mengambil keputusan investasi. Pihak-pihak terkait seperti manajer investasi, perusahaan sekuritas, dan lainnya juga dapat melakukan profiling perilaku investor agar dapat memberikan rekomendasi pengambilan keputusan kepada investor.

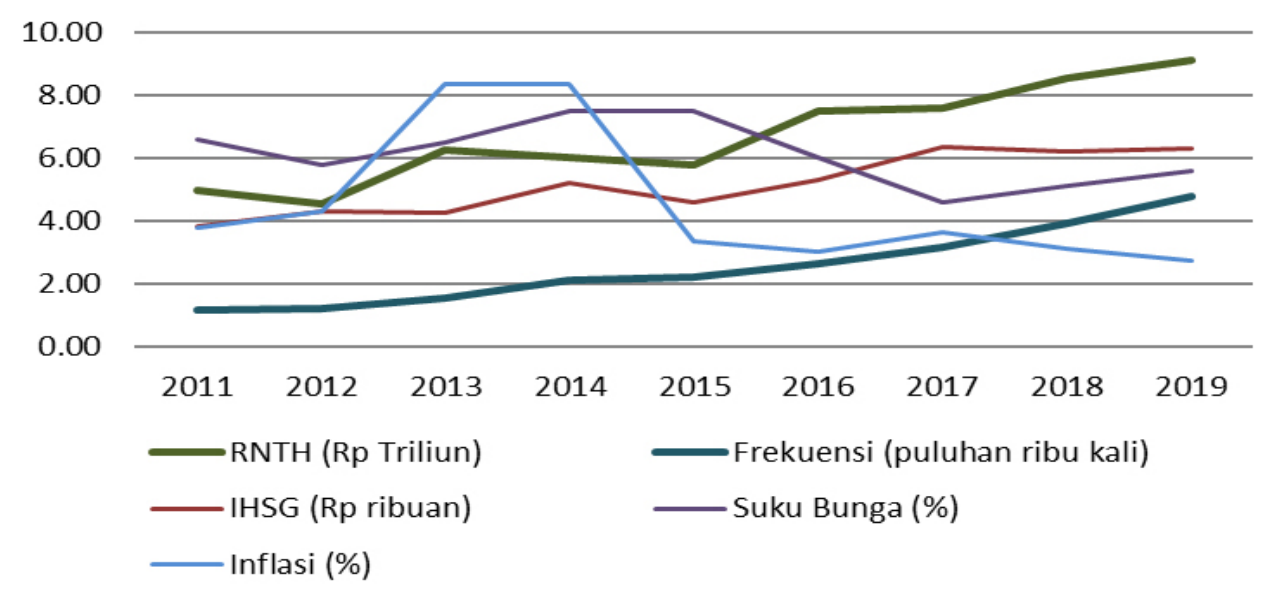

Gambar 1. Rata-rata nilai transaksi harian, rata-rata frekuensi transaksi harian, indeks harga saham gabungan, suku bunga, dan inflasi tahun 2011-2019 (BPS, 2019) 
Penelitian ini bertujuan menganalisis pengaruh kepribadian investor terhadap preferensi risiko, menganalisis kepribadian investor terhadap perilaku investor dalam menggunakan online trading, dan menganalisis pengaruh perilaku penggunaan online trading terhadap preferensi risiko investor. Ruang lingkup penelitian ini adalah behavioral finance, kepribadian investor, online trading dan juga preferensi risiko investor dalam mengambil keputusan investasi.

\section{METODE PENELITIAN}

Penelitian ini dikembangkan dari fenomena yang terjadi dan literatur-literatur terdahulu yang berkaitan dengan kepribadian, perilaku penggunaan online trading, dan preferensi risiko investor. Fenomena yang terjadi pada masyarakat yaitu, adanya perkembangan teknologi digital yang mempermudah kegiatan manusia dalam segala aspek, salah satunya berinvestasi. Kemudahan yang didapatkan dari fasilitas online trading, menyebabkan meningkatnya penggunaan online trading oleh investor. Online trading digunakan oleh investor untuk membuat keputusan investasi, dimana dalam membuat keputusan, investor dipengaruhi oleh kepribadian, perilaku penggunaan online trading, dan preferensi risikonya.

Jenis data yang digunakan pada penelitian ini adalah data primer yang diperoleh melalui penyebaran kuesioner kepada responden investor yang aktif di media sosial Instagram, Twitter, dan Telegram dengan kriteria responden merupakan investor yang memiliki instrumen investasi seperti saham, obligasi, reksadana, dan lainnya. Kriteria responden lainnya adalah responden menggunakan aplikasi investasi ataupun online trading. Pengumpulan data melalui sosial media ini diharapkan bisa mewakili seluruh investor individu di Indonesia yang aktif bertransaksi secara online baik pemula maupun yang sudah berpengalaman. Penelitian ini akan dilakukan pada bulan Februari 2020 - April 2020.

Penarikan sampel pada penelitian ini menggunakan metode non-probability sampling dengan teknik purposive sampling. Pemilihan metode non-probability sampling dikarenakan tidak diperolehnya data investor yang menggunakan online trading secara aktif. Penentuan jumlah sampel yang digunakan dalam penelitian ini ditentukan dengan cara mengalikanjumlah indikator dengan range 5-10 (Roscoe dalam Sugiyono,
2016). Indikator penelitian ini berjumlah 48 indikator yang kemudian dikalikan dengan range paling minimal yaitu 5. Perkalian tersebut menghasilkan sampel pada penelitian ini berjumlah 240 investor responden.

Metode yang digunakan untuk analisis data yaitu analisis deskriptif dan analisis hubungan variabel menggunakan SEM-PLS. Kuesioner dilakukan pengujian validitas dan reliabilitas pertanyaannya terlebih dahulu sebelum dikirimkan kepada responden. Berdasarkan kajian literatur dan fenomena yang terjadi, disusun hipotesis penelitian sebagai berikut:

H1 : Kepribadian memiliki pengaruh terhadap sikap preferensi risiko investor

H1a : Kepribadian openness to experience berpengaruh terhadap sikap preferensi risiko investor

H1b : Kepribadian conscientiousness berpengaruh terhadap sikap preferensi risiko investor

H1c : Kepribadian extraversion berpengaruh terhadap sikap preferensi risiko investor

H1d : Kepribadian agreeableness berpengaruh terhadap sikap preferensi risiko investor

H1e : Kepribadian neuroticism berpengaruh terhadap sikap preferensi risiko investor

H2 : Kepribadian memiliki pengaruh terhadap perilaku penggunaan online trading

$\mathrm{H} 2 \mathrm{a}$ : Kepribadian openness to experience memiliki pengaruh terhadap perilaku penggunaan online trading

$\mathrm{H} 2 \mathrm{~b}$ : Kepribadian conscientiousness memiliki pengaruh terhadap perilaku penggunaan online trading

H2c : Kepribadian extraversion memiliki pengaruh terhadap perilaku penggunaan online trading

$\mathrm{H} 2 \mathrm{~d}$ : Kepribadian agreeableness memiliki pengaruh terhadap perilaku penggunaan online trading

$\mathrm{H} 2 \mathrm{e} \quad$ : Kepribadian neuroticism memiliki pengaruh terhadap perilaku penggunaan online trading

H3 Perilaku penggunaan Online trading memiliki pengaruh terhadap sikap toleransi risiko investor.

Hipotesis ini didukung penelitian-penelitian terdahulu. Tauni et al. (2017) pada penelitiannya membuktikan bahwa adanya hubungan positif antara perolehan informasi dan perilaku perdagangan, yang berarti 
semakin sering investor memperoleh investasi maka semakin sering mereka melakukan investasi. Yang et al. (2012) menunjukkan bahwa investor dengan toleransi risiko moderat memiliki hubungan dengan kepercayaan dan volume perdagangan yang dilakukan investor. Penelitian oleh Pak dan Mahmood (2015) menunjukkan hasil bahwa openness to experience berpengaruh positif dan signifikan terhadap toleransi risiko. Extraversion memiliki pengaruh negatif signifikan pada tingkat toleransi risiko. Variabel agreeableness, conscientiousness dan neuroticism memiliki tidak signifikan terhadap toleransi risiko investor. Putri et al. (2017) dengan judul Pengaruh Faktor Kepribadian terhadap Toleransi Risiko Keputusan Investasi Saham menunjukkan hasil yang berbeda yaitu bahwa kepribadian(openness to experience, conscientiousness, extraversion, agreeableness, dan neuroticism) tidak memiliki pengaruh terhadap toleransi risiko investor karena investor yang menjadi responden dalam penelitian ini cenderung rasional dalam pengambilan keputusan. Berdasarkan kajian teoritis dan empiris dapat disusun kerangka pemikiran pada Gambar 2.

\section{HASIL}

\section{Karakteristik Responden}

Data karakteristik responden digunakan untuk melihat keberagaman responden yang menjadi sampel penelitian ini. Responden investor dalam penelitian ini adalah kalangan investor yang menggunakan aplikasi investasi dalam melakukan transaksi. Data karakteristik responden disajikan dalam Tabel 1. Responden penelitian ini berjumlah 240 responden dengan proporsi 75 persen laki-laki dan 25 persen perempuan. Responden rata-rata berusia 20-30 tahun, ini merupakan usia yang produktif. Responden sebagian besar berasal dari pulau Jawa dengan jumlah terbesar berasal dari provinsi Jawa Barat. Data dari sampel penelitian ini cukup mencerminkan data populasi yang tercatat pada Bursa Efek Indonesia (BEI) dimana investor Indonesia 79 persen berjenis kelamin laki-laki, didominasi oleh investor berusia kurang dari 30 tahun, dan 70 persen merupakan penduduk pulau Jawa. Sebagian besar responden berprofesi sebagai pegawai BUMN/Swasta. Mayoritas pendapatan responden adalah $>$ Rp50 juta pertahun. Sebagian besar responden memiliki pengalaman berinvestasi selama $>2$ tahun. Aplikasi investasi yang paling banyak digunakan oleh responden adalah aplikasi IPOT ataupun Indo Primer Online Technology. Sebanyak 92 persen responden penelitian ini memiliki instrumen saham dan sekitar 68 persen responden penelitian ini memiliki lebih dari satu.

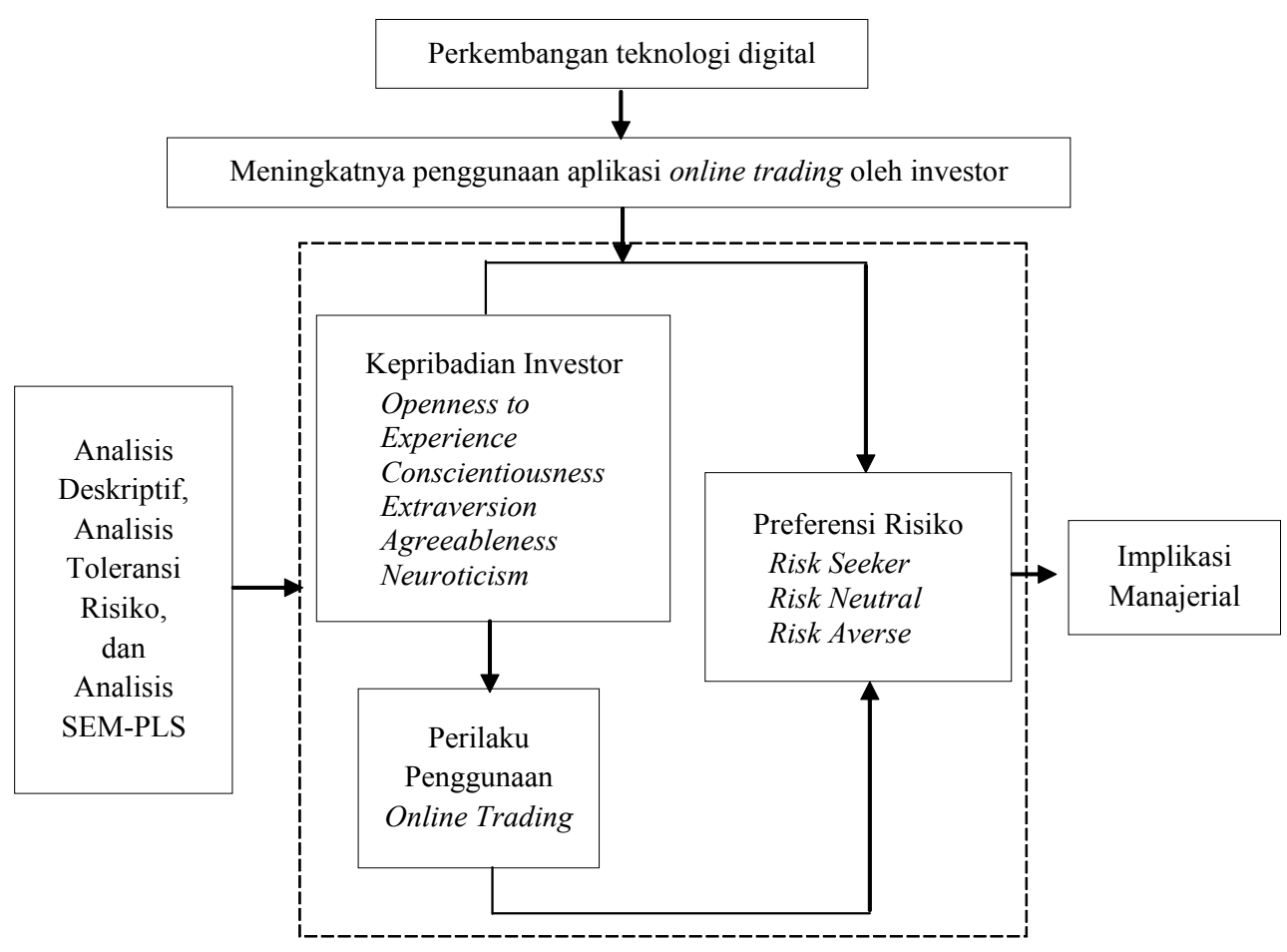

Gambar 2. Kerangka pemikiran penelitian 
Tabel 1. Karakteristik responden

\begin{tabular}{|c|c|c|}
\hline Karakteristik & $\mathrm{n}$ & $\%$ \\
\hline \multicolumn{3}{|l|}{ Jenis Kelamin } \\
\hline Laki-laki & 181 & 75,4 \\
\hline Perempuan & 59 & 24,6 \\
\hline \multicolumn{3}{|l|}{ Usia } \\
\hline$<20$ tahun & 17 & 7,1 \\
\hline 20-30 tahun & 192 & 80,0 \\
\hline $31-40$ tahun & 27 & 11,3 \\
\hline 41-50 tahun & 3 & 1,3 \\
\hline$>50$ tahun & 1 & 0,4 \\
\hline \multicolumn{3}{|l|}{ Provinsi } \\
\hline Sumatera Utara & 16 & 6.7 \\
\hline Sumatera Barat & 6 & 2,5 \\
\hline Banten & 20 & 8,3 \\
\hline DKI Jakarta & 42 & 17,5 \\
\hline Jawa Barat & 50 & 20,8 \\
\hline Jawa Tengah & 21 & 8,8 \\
\hline Jawa Timur & 30 & 12,5 \\
\hline DI Yogyakarta & 7 & 2,9 \\
\hline Bali & 7 & 2,9 \\
\hline Sulawesi Selatan & 6 & 2,5 \\
\hline Lainnya & 35 & 14,6 \\
\hline \multicolumn{3}{|l|}{ Pekerjaan } \\
\hline Pegawai Negeri Sipil & 21 & 8,8 \\
\hline Pegawai BUMN/Swasta & 105 & 43,8 \\
\hline Wirausaha & 26 & 10,8 \\
\hline Freelance & 27 & 11,3 \\
\hline Mahasiswa/Pelajar & 55 & 22,9 \\
\hline Lainnya & 6 & 2,5 \\
\hline
\end{tabular}

\section{Analisis SEM-PLS}

Dalam SEM-PLS, variabel harus terlebih dahulu dilakukan evaluasi model pengukuran (outer model), yaitu dengan melihat validitas dan reliabilitas model dari indikator-indikator variabel. Evaluasi yang dilakukan adalah convergent validity dengan syarat nilai outer loading $>0,5$ dan $\mathrm{AVE}>0,5$. Jika outer loading $>0,5$ namun nilai AVE $<0,5$ maka perlu dilakukan dropping pada indikator dengan nilai yang paling mendekati 0,5 (Abdillah dan Hartono, 2015). Discriminant validity diukur melalui nilai cross loading yang dihitung pada SEM-PLS dan Construct reliability dengan syarat composite reliability $>0.7$ atau pun cronbach's alpha bernilai $\alpha>0,6$. Dari evaluasi outer model ini, terdapat beberapa indikator variabel yang tidak memenuhi syarat yang akhirnya dilakukan dropping dan menjadikan model baru. Perubahan model dapat dilihat pada Gambar 3.

\begin{tabular}{|c|c|c|}
\hline Karakteristik & $\mathrm{n}$ & $\%$ \\
\hline \multicolumn{3}{|c|}{ Pendapatan Pertahun } \\
\hline$<$ Rp 50 juta & 120 & 50,5 \\
\hline Rp $50-100$ juta & 66 & 27,5 \\
\hline Rp 101- 150 juta & 29 & 12,1 \\
\hline Rp $151-200$ juta & 8 & 3,3 \\
\hline$>$ Rp 200 juta & 17 & 7,1 \\
\hline \multicolumn{3}{|c|}{ Pengalaman Berinvestasi } \\
\hline$<2$ tahun & 153 & 63,7 \\
\hline 2-4 tahun & 68 & 28,3 \\
\hline $5-7$ tahun & 12 & 5,0 \\
\hline 8-10 tahun & 6 & 2,5 \\
\hline$>10$ tahun & 1 & 0,4 \\
\hline \multicolumn{3}{|l|}{ Aplikasi Investasi } \\
\hline IPOT & 89 & 37,1 \\
\hline Stockbit & 20 & 8,3 \\
\hline Bareksa & 9 & 3,8 \\
\hline Bibit & 24 & 10,0 \\
\hline MOST & 22 & 9,2 \\
\hline POEMS & 15 & 6,3 \\
\hline HOTS & 19 & 7,9 \\
\hline E Smart & 10 & 4,2 \\
\hline RHB Trade Smart & 6 & 2,5 \\
\hline Lainnya & 26 & 10,8 \\
\hline \multicolumn{3}{|l|}{ Jenis Investasi } \\
\hline Saham & 221 & 92 \\
\hline Obligasi & 42 & 17,2 \\
\hline Reksadana & 111 & 46,2 \\
\hline Komoditas & 27 & 11,3 \\
\hline Lainnya & 5 & 2 \\
\hline
\end{tabular}

Indikator yang mendapat perlakuan dropping adalah indikator $\mathrm{OP} 2, \mathrm{OP} 3, \mathrm{CO} 2, \mathrm{CO} 3, \mathrm{AG} 4$, digunakan karena tidak memenuhi syarat convergent validity yaitu loadings faktor $<0,5$ dan AVE $<0,5$. Dari total 48 indikator, tersisa 41 indikator yang memenuhi syarat untuk dilakukan uji inner model ataupun uji hipotesis. Setelah dilakukan pengujian model pengukuran (outer model) selanjutnya dilakukan pengujian model struktural (inner model). Pengujian model struktural (inner model) dilakukan untuk memprediksi hubungan kausal antara variabel ataupun pengujian hipotesis (Abdillah dan Hartono, 2015). Pengujian inner model dilakukan dengan melihat nila $R$-Square yang merupakan uji goodness-fit model untuk konstruk dependen, uji t, serta signifikansi dari koefisien parameter jalur struktural melalui hasi boostraping. Nilai $R$-Square disajikan pada Tabel 2. 




Gambar 3. Model struktural sebelum dan setelah dropping 
Tabel 2. Nilai R-Square

\begin{tabular}{lc}
\hline Variabel Laten & R-Square \\
\hline Perilaku Online Trading & 0,072 \\
Preferensi risiko & 0,144 \\
\hline
\end{tabular}

Nilai $R$-Square pada variabel perilaku penggunaan online trading sebesar 0,072 memiliki arti bahwa variabel lima kepribadian mampu menjelaskan perilaku penggunaan online trading investor sebesar 7,4 persen dan sisanya sebesar 92,8 persen dijelaskan oleh faktor lainnya. Variabel preferensi risiko memiliki nilai $R$-Square sebesar 0,144 yang berarti bahwa variabel lima kepribadian dan perilaku penggunaan online trading mampu menjelaskan preferensi risiko sebesar 14,4 persen dan sisanya sebesar 85,6 persen dijelaskan oleh faktor lainnya. Nilai $R$-Square pada penelitian ini kecil dikarenakan banyaknya faktor yang mempengaruhi perilaku keuanngan seseorang seperti faktor demografi, literasi keuangan, niat berinvestasi, bias overconfidence, perolehan informasi dan lainnya (Amaiyah dan Ismanto, 2020; Tauni et al, 2017)

\section{Pengaruh Lima Dimensi Kepribadian terhadap Perilaku Penggunaan Online Trading}

Pengaruh antar variabel dependen dan independen dapat dijelaskan melalui tabel Path Coefficient dengan melihat nilai $T$ Statistic $\geq T$ Table $(1,96)$ dan nilai $P$ Values $<0,05$ (tingkat keyakinan 95 persen) untuk mengetahui signifikansi pengaruh, dan nilai Original Sampel untuk mengetahui arah pengaruh apakah berpengaruh positif atau negatif.

Tabel 3 menyajikan data Path Coefficient pengaruh lima kepribadian terhadap perilaku penggunaan online trading. Nilai original sample, $T$ Statistics, dan $P$ Values menunjukkan bahwa hanya kepribadian openness to experience yang memiliki pengaruh positif dan signifikan terhadap prilaku penggunaan online trading. Penelitian oleh Tauni et al. (2016) menunjukkan hasil yang sama dimana kepribadian openness to experience mempengaruhiperilaku transaksi investor. Empat dimesi variabel kepribadian lainnya yaitu conscientiousness, extraversion, agreeableness, dan neuroticism tidak memiliki pengaruh yang signifikan terhadap perilaku penggunaan online trading. Hasil ini memberikan keputusan Hasil ini memberikan keputusan hipotesis terima hipotesis 1a (H1a) dan tolak hipotesis $1 \mathrm{~b}(\mathrm{H} 1 \mathrm{~b})$, hipotesis 1c (H1c), hipotesis 1d (H1d), dan hipotesis 1e (H1e).
Orang yang memiliki kepribadian terbuka terhadap sesuatu cenderung menyelidiki segala sesuatu dengan penuh semangat dan penuh rasa ingin tahu. Hal ini membuat individu dengan kepribadian terbuka akan menyelidiki informasi secara menyeluruh, sehingga membuat sering menggunakan fasilitas online trading. Kepribadian conscientiousness, extraversion, agreeableness, dan neuroticism tidak memiliki pengaruh yang signifikan dapat disebabkan karena investor yang menjadi responden merupakan investor yang sudah cukup paham bagaimana untuk mengambil keputusan yang baik. Hal ini membuat investor dapat membuat keputusan yang rasional untuk investasi yang dilakukan. Kepribadian conscientiousness merupakan kepribadian yang mencerminkan ketelitian dan kehatihatian yang merupakan hal yang harus dimiliki semua investor dalam membuat keputusan dan ini membuat investor harus mencari informasi lebih dari satu sumber tidak hanya dari platform online trading, yaitu seperti media massa dan laporan keuangan perusahaan. Extraversion dan agreeableness merupakan kepribadian yang akan muncul ketika seseorang berinteraksi dengan orang lain. Rasionalitas membuat kepribadian ini tidak dapat mempengaruhi perilaku investor dalam bertransaksi menggunakan online trading. Kepribadian neuroticism ataupun sifat mudah cemas dan gelisah membuat investor didorong untuk bersikap rasional dan menganalisis aset investasi lebih dalam. Ketidakpastian membuat investor mudah cemas, maka dengan itu untuk meminimalisir ketidakpastian investor harus lebih banyak melakukan analisis external maupun internal pada aset investasi.

\section{Pengaruh Lima Kepribadian terhadap Preferensi Risiko}

Path Coefficient lima kepribadian terhadap preferensi risiko yang ditunjukkan pada Tabel 4 menunjukkan bahwa hanya variabel openness to experience yang memiliki pengaruh positif dan signifikan terhadap preferensi risiko investor. Hasil ini sesuai dengan penelitian oleh Pak dan Mahmood (2015) dimana kepribadian opennes to experience memiliki hubungan yang positif dan signifikan terhadap preferensi risiko investor. Variabel conscientiousness, extraversion, agreeableness, dan neuroticism juga menunjukkan tidak adanya pengaruh yang signifikan terhadap preferensi risiko. Hasil ini memberikan keputusan hipotesis terima hipotesis $2 \mathrm{a}(\mathrm{H} 2 \mathrm{a})$ dan tolak hipotesis $2 \mathrm{~b}(\mathrm{H} 2 \mathrm{~b})$, hipotesis $2 \mathrm{c}(\mathrm{H} 2 \mathrm{c})$, hipotesis $2 \mathrm{~d}(\mathrm{H} 2 \mathrm{~d})$, dan hipotesis $2 \mathrm{e}(\mathrm{H} 2 \mathrm{e})$. 
Tabel 3. Path coefficient lima kepribadian terhadap perilaku penggunaan online trading

\begin{tabular}{lccccc}
\hline & Original Sample $(\mathrm{O})$ & Sample Mean $(\mathrm{M})$ & $\begin{array}{c}\text { Standard } \\
\text { Deviation }(\mathrm{STDEV})\end{array}$ & $\begin{array}{c}\text { T Statistics } \\
(|\mathrm{O} / \mathrm{STDEV}|)\end{array}$ & $\mathrm{P}$ Values \\
\hline $\mathrm{OP} \rightarrow \mathrm{ON}$ & 0,206 & 0,214 & 0,069 & 2,991 & 0,003 \\
$\mathrm{CO} \rightarrow \mathrm{ON}$ & 0,048 & 0,039 & 0,093 & 0,512 & 0,609 \\
$\mathrm{EX} \rightarrow \mathrm{ON}$ & 0,093 & 0,088 & 0,101 & 0,92 & 0,358 \\
$\mathrm{AG} \rightarrow \mathrm{ON}$ & $-0,092$ & $-0,078$ & 0,105 & 0,883 & 0,378 \\
$\mathrm{NE} \rightarrow \mathrm{ON}$ & $-0,05$ & $-0,061$ & 0,086 & 0,578 & 0,563 \\
\hline
\end{tabular}

Tabel 4. Path coefficient lima kepribadian terhadap preferensi risiko

\begin{tabular}{lccccc}
\hline & Original Sample $(\mathrm{O})$ & Sample Mean $(\mathrm{M})$ & $\begin{array}{c}\text { Standard } \\
\text { Deviation }(\text { STDEV })\end{array}$ & $\begin{array}{c}\text { T Statistics } \\
(|\mathrm{O} / \mathrm{STDEV}|)\end{array}$ & $\mathrm{P}$ Values \\
\hline $\mathrm{OP} \rightarrow \mathrm{TR}$ & 0,173 & 0,171 & 0,082 & 2,12 & 0,034 \\
$\mathrm{CO} \rightarrow \mathrm{TR}$ & 0,033 & 0,033 & 0,092 & 0,358 & 0,721 \\
$\mathrm{EX} \rightarrow \mathrm{TR}$ & 0,054 & 0,057 & 0,074 & 0,736 & 0,462 \\
$\mathrm{AG} \rightarrow \mathrm{TR}$ & $-0,098$ & $-0,102$ & 0,09 & 1,088 & 0,277 \\
$\mathrm{NE} \rightarrow \mathrm{TR}$ & $-0,07$ & $-0,08$ & 0,072 & 0,97 & 0,332 \\
\hline
\end{tabular}

Hasil ini memiliki arti bahwa semakin seseorang bersikap terbuka terhadap hal-hal baru, maka orang tersebut memiliki preferensi risiko yang tinggi ataupun bersikap risk seeker. Hal ini terjadi karena orang dengan kepribadian openness to experience cenderung bersemangat dan memiliki rasa ingin tahu yang tinggi yang membuat mereka memiliki ekspektasi tinggi atas investasi yang mereka miliki hingga rela mengambil untuk risiko. Hasil ini juga berhubungan dengan hasil hipotesis $1 \mathrm{a}$, dimana hanya openness to experience yang memengaruhi variabel dependen. Kedua variabel dependen pada hipotesis 1a dan hipotesis 2a juga memiliki kaitan terhadap pengambilan keputusan investasi yang akan dibuktikan pada hipotesis 3 .

Kepribadian conscientiousness akan lebih rasional dalam mengambil keputusan, investor akan selalu melakukan analisis terlebih dahulu mengenai sebuahaset sebelum melakukan transaksi. Kepribadian extraversion dan agreeableness ataupun sikap mudah bergaul dan sikap lemah lembut tidak memiliki hubungan dengan bagaimana investor membuat keputusan. Hal ini tidak menentukan emosi seseorang dalam bertindak. Kedua kepribadian menggambarkan bagaimana sikap mereka dalam berinteraksi dengan orang-orang sekitar, namun tampaknya pengaruh orang sekitar tidak memberikan dampak besar terhadap keputusan yang diambil investor dimana ini merupakan tanda bahwa investor bersikap rasional dan mempertimbangkan keputusannya dengan analisis informasi mendalam tanpa pengaruh orang lain. Kepribadian neuroticism ataupun rasa cemas tampak memiliki hubungan dengan bagaimana seseorang membuat keputusan terkait risiko, lebih tepatnya hubungan yang negatif. Namun pengaruhnya tidak signifikan karena walaupun investor dihadapi dengan kecemasan dan ketakutan, investor tetap berusaha untuk menganalisis terlebih dahulu sebelum mengambil keputusan agar tidak ceroboh.

\section{Pengaruh Perilaku Penggunaan Online Trading terhadap Preferensi Risiko}

Path Coefficient perilaku penggunaan online trading terhadap preferensi risiko investor pada Tabel 5 menunjukkan bahwa perilaku penggunaan online trading berpengaruh positif signifikan terhadap preferensi risiko. Perilaku penggunaan online trading oleh investor dapat menentukan bagaimana tingkat preferensi risiko yang dimilikinya. Hasil ini memberikan keputusan hipotesis terima hipotesis $3(\mathrm{H} 3)$.

Hasil penelitian ini sesuai dengan penelitian yang dilakukan Oh et al. (2008) yang menyebutkan bahwa perilaku online oleh investor membuat investor tidak lagi mempertimbangkan return, tetapi kenyamanan dan biaya transaksi yang rendah menyebabkan investor berani mengambil risiko. Ini menunjukkan bahwa semakin seseorang sering menggunakan dan bertransaksi investasi menggunakan online trading, maka semakin tinggi toleransi yang mereka miliki ataupun mereka bersikap risk seeker. Semakin banyak dan semakin mudah informasi yang tersedia, membuat investor semakin berani untuk mengambil risiko. Intensitas penggunaan online trading membuat 
investor terdorong untuk melakukan transaksi. Hasil ini memiliki kesesuaian dengan hipotesis 1a dan hipotesis 2a, dimana kepribadian openness to experience juga memiliki pengaruh terhadap preferensi risiko investor. Jika ditarik dari garis model struktural perilaku penggunaan online trading membawa pengaruh yang diberikan kepribadian openness to experience dalam mempengaruhi preferensi risiko investor. Artinya adalah perilaku penggunaan online trading oleh investor dapat membuat investor semakin risk seeker karena adanya pengaruh dari kepribadian openness to experience yang dimiliki investor.

\section{Implikasi Manajerial}

Bagi investor, sesuai dengan hasil penelitian, kepribadian openness to experience merupakan satusatunya kepribadian yang berpengaruh terhadap perilaku online trading dan preferensi risiko investor. Kepribadian openness to experience mendorong investor bersikap risk seeker, maka disarankan investor dengan kepribadian ini sebaiknya mengontrol rasa penasaran dan ingin tahu. Investor sebaiknya berhatihati dalam menggunakan online trading. Online trading kebanyakan hanya menyajikan informasi fluktuasi harga yang dapat dianalisis menggunakan analisis teknikal, untuk mempertimbangkan suatu risiko investasi analisis fundamental, isu-isu perekonomian dan politik, dan pertimbangan-pertimbangan rasional lainnya harus tetap dilakukan. Manajer investasi, perusahaan sekuritas, dan perusahaan penyedia informasi investasi dapat memanfaatkan hasil penelitian ini dengan melihat perilaku investor yang menjadi responden penelitian ini. Profiling risiko pada investor dapat dilakukan untuk memberikan rekomendasi keputusan investasi yang akan dilakukan investor. Ini sangat membantu investor agar mudah melakukan diversifikasi aset sesuai dengan tingkat preferensi risiko yang mereka miliki. Tidak hanya profiling risiko, namun melihat perilaku investor terhadap informasi yang diberikan perusahaan sekuritas melalui aplikasi investasi yang disediakan untuk investor melakukan transaksi dan mencari informasi.

Tabel 5. Path coefficient perilaku penggunaan online trading terhadap preferensi risiko

\begin{tabular}{cccccc}
\hline & Original Sample $(\mathrm{O})$ & Sample Mean $(\mathrm{M})$ & $\begin{array}{c}\text { Standard } \\
\text { Deviation }(\text { STDEV) }\end{array}$ & $\begin{array}{c}\text { T Statistics } \\
(\mid \mathrm{O} / \text { STDEV } \mid)\end{array}$ & P Values \\
\hline $\mathrm{ON} \rightarrow \mathrm{TR}$ & 0,257 & 0,257 & 0,073 & 3,502 & 0,001 \\
\hline
\end{tabular}

\section{KESIMPULAN DAN SARAN}

\section{Kesimpulan}

Berdasarkan hasil dari penelitian ini, dapat ditarik beberapa kesimpulan bahwa dari kelima dimensi kepribadian tampaknya tidak banyak memengaruhi bagaimana investor berperilaku dalam menggunakan fasilitas online dan juga bagaimana investor membuat keputusan investasi. Kepribadian openness to experience ataupun kepribadian terbuka terhadap sesuatu merupakan satu-satunya kepribadian dari The Big Five Personality yang memiliki pengaruh terhadap perilaku penggunaan online trading dan tingkat preferensi risiko investor. Perilaku penggunaan online trading oleh investor memiliki pengaruh dan dapat meningkatkan preferensi risiko investor yang berarti bahwa semakin intens penggunaan online trading oleh investor maka semakin bersikap risk seeker.

\section{Saran}

Ada beberapa saran yang dapat menjadi masukan beberapa pihak. Investor sebagai pengguna online trading disarankan untuk lebih bijak dalam memproses informasi yang disediakan. Analisis fundamental, teknikal dan membaca berita merupakan hal yang harus dilakukan agar tidak mengalami kerugian. Manajer investasi dapat melalui profiling risiko dan juga dari bagaimana investor berinteraksi dengan fasilitas dan informasi yang disediakan. Perusahaan sekuritas dan institusi pasar modal dapat melakukan survey berkala kepada investor mengenai bagaimana investor berperilaku terhadap fasilitas dan informasi yang tersedia dan terhadap tingkat pengetahuan investor atas pasar modal. Kekurangan penelitian ini adalah tidak melihat pengaruh variabel lainnya yang dapat berpengaruh terhadap kepribadian seperti faktor demografi, niat berinvestasi, literasi keuangan, bias emosi, bias kognitif, dan lainnya. Peneliti selanjutnya dapat menambahkan variabel-valiabel tersebut untuk diteliti. 


\section{DAFTAR PUSTAKA}

Abdillah W, Hartono, J. 2015. Partial least square (PLS) - alternatif structural equation modeling (SEM) dalam penelitian bisnis. Yogyakarta: Penerbit Andi.

Abreu M, Mendes V. 2012. Information, overconfidence and trading: Do the sources of information matter? Journal Economic Psyicology 33(4):868-881.

Amaiyah NI, Ismanto H. 2020. Literasi Keuangan dan Perilaku Keuangan Karyawan Swasta di Kabupaten Jepara. Jurnal Aplikasi Manajemen dan Bisnis 6(3):468-477.

[BPS] Badan Pusat Statistik. 2020. BI Rate, Tahun 2005-2020. http://bps.go.id. [ 7 Sept 2020].

Chopde S, Kulkarni N. 2017. Impact of behavioral biases on investment decisions of individual investors in Mumbai a sample study. International Conference On Emanations in Modern Technology and Engineering (ICEMTE2017). Maharashtra, 4th to 5th March 2017. Maharashtra: Mira Bhayandar. 7-40.

Conlin A, Kyröläinen P, Kaakinen M, Järvelin MR, Perttunen J, Svento R. 2015. Personality traits and stock market participation. Journal Empirical Finance, 33:34-50.

Didier T, Schmukler SL. 2014. Financial development in Asia: beyond aggregate indicators. World Bank Policy Research. Washington, DC. (6761).

Durand R., Paolella L. 2013. Category stretching: Reorienting research on categories in strategy, entrepreneurship, and organization theory. Journal Management Study 50(6): 1100-1123.

Goldberg LR. 1992. The development of markers for the big-five factor structure. Psychological Assessment 4(1):26-42.

Halim A. 2005. Analisis investasi. Jakarta: Salemba Empat.

Indriani R. 2014. Pengaruh kepribadian terhadap kepuasan perkawinan wanita dewasa awal pada fase perkawinan ditinjau dari teori trait kepribadian Big Five. Jurnal Psikologi Klinis dan Kesehatan Mental 3(1):33-39.

Kahneman D, Tversky A. 1979. Prospect theory: An analysis of decision under risk. Econometrica 143-172.
Lolibl C, Hira. TK. 2011. Know your subject: A gendered perspective on investor information search. Journal of Behavioral Financ 12(3):117130.

Oh NY, Parwada JT, Walter TS. 2008. Investors' trading behavior and performance: Online versus nononline equity trading in Korea. Pacific-Basin Finance Journal 185-205.

Pak O, Mahmood M. 2015. Impact of personality on risk tolerance and investment decisions: A study on potential investors of Kazakhstan. International Journal of Commerce and Management 25(4):370-384.

Putri FK, Hakim MS. 2017. Pengaruh faktor kepribadian terhadap toleransi risiko keputusan investasi saham. Jurnal Sains Dan Seni ITS 6(1).

Rinandiyana LR, Fahmi AN, Kusnandar DL. 2020. Experienced regret dan risk tolerance dalam membentuk perilaku perdagangan saham. Forum Ekonomi 22(1):44-48.

Tauni MZ, Rao ZUR, Fang H, Mirza SS, Memon ZA., Jebran K. 2017. Do investor's Big Five personality traits influence the association between information acquisition and stock trading behavior?. China Finance Review International 7(4):450-477.

Vidayana. 2012. Faktor-faktor yang mempengaruhi minat investor dalam menggunakan sistem perdagangan saham online. Journal of Business Strategy and Execution 5(1):55-76.

Wandrial S. 2014. Tipe kepribadian pada mahasiswa kelas manajemen Universitas Bina Nusantara dengan menggunakan Myers-Briggs Type Indicator (MBTI). Binus Business Review 5(1):344-354.

Wulandari DA, Iramani R. 2014. Studi experienced regret, risk tolerance, overconfidence dan risk perception pada pengambilan keputusan dosen ekonomi, Journal of Business \& Banking 4(1):55-66.

Wulfmeyer S. 2016. Irrational mutual fund managers: Explaining differences in their behavior. Journal Behavioral Finance 17(2):99-123

Yang S, Hsu Y, Tu C. 2012. How do traders influence investor confidence and trading volume? A dyad study in the futures market. Emerging Markets Finance and Trade 48(S3):23-34. 